\title{
Anatomia da academia: cultura comercial e disciplina do corpo
}

Ileana Wenetz*

\begin{abstract}
Resumo: Esta resenha propõe-se a apresentar o livro Anatomia da Academia: Cultura comercial e disciplina do corpo, de Roberta Sassatelli. A obra destaca diferentes perspectivas teóricas, por meio de um estudo etnográfico em duas academias de Florença, Itália. A autora realiza uma abordagem sobre o consumo, observando o fitness, o corpo e a cultura comercial. Ainda, discute valores da subjetividade moderna, buscando compreender o percurso que os clientes seguem na academia para sua socialização.
\end{abstract}

Palavras-chave: Academia. Corpo. Cultura comercial. Forma física.

\section{INTRODUÇÃO}

Em nossos dias, as academias constituem lugares da moda, tão comuns e corriqueiros como quaisquer outros espaços que oferecem algum serviço. Algumas delas apresentam uma ampla infra-estrutura com restaurantes e lojas ou fazem parte dos modernos complexos residenciais. Nesses locais, homens e mulheres de diferentes idades e classes sociais desenvolvem atividades físicas ou compram produtos específicos. Diferentes meios de comunicação promovem a idéia de uma atividade física prazerosa, sem esforço nem sacrifícios, construindo um "glamour" da prática esportiva e de um estilo de vida.

Paradoxalmente, este espaço muito comum e cotidiano tem recebido poucas análises qualitativas e de cunho etnográfico. Há estudos sobre as técnicas de treinamento e de musculação e sobre a gestão esportiva nas academias. Tenho observado, no contexto

\footnotetext{
Bolsista da CAPES/CNPq-IEL Nacional-Brasil. ESEF/UFRGS. Porto Alegre, RS. Brasil. E-mail: ilewenetz@gmail.com
} 
brasileiro, uma ausência de pesquisas que tratem das relações de gênero, de idade e de raça sobre os sentidos atribuídos ao corpo e, particularmente, as aprendizagens sociais que acontecem nesses ambientes.

Nesse sentido, o trabalho de Roberta Sassatelli é original ao abordar diferentes aspectos das academias e suas características sociológicas. Roberta realiza seu estudo utilizando diferentes perspectivas e articula, de forma pertinente, diversos autores como Goffman, Foucault, Bourdieu, Marx, Weber, Simmel, Elias e Dunning, etc. A autora centra-se no conceito de consumo, tratando a academia como a "parte mais atual da cultura comercial do exercício físico" (SASSATELLI, 2000, p.10). Assim, utiliza uma linguagem específica e simples referindo-se aos sujeitos que freqüentam academias como clientes e não como alunos, e à academia, como uma empresa.

$\mathrm{O}$ estudo faz parte de sua pesquisa de doutorado. O trabalho etnográfico foi desenvolvido durante nove meses na cidade italiana de Florença. ${ }^{1}$ A autora analisou duas academias (a mais familiar e a mais moderna), posicionando-se como uma freqüentadora comum e posteriormente como pesquisadora. Nesta última posição, realizou entrevistas às pessoas freqüentadoras desses locais.

O livro é dividido em seis capítulos. No capítulo primeiro, a autora destaca aspectos gerais do ingresso à academia, focalizando tanto os recursos do local e da organização espaço-temporal, como a função dos vestiários e a interação que neles acontece. Ainda, observa a modalidade do exercício. No capítulo seguinte, aborda a organização dos exercícios e o comportamento expressivo que reúne regras implícitas prescritas aos freqüentadores.

O capítulo três detalha características do exercitar-se com sucesso, implicadas não só no aprender determinados exercícios, mas no descobrir qual o sentido desse movimento e qual seu significado. Assim, o treinamento pode ser a concretização de um projeto de melhora do próprio corpo. No capítulo quatro, a autora

\footnotetext{
${ }_{1}^{1}$ Florença foi escolhida pela autora por ser a cidade italiana que possui o maior índice academias por habitantes, a saber, 12,72 academias por 100.000 habitantes.

Movimento, Porto Alegre, v. 13, n. 03, p. 245-259, setembro/dezembro de 2007.
} 
destaca o valor do treinamento, a eficácia, a eficiência e o conhecimento sobre o corpo, além de caracterizar a prática do fitness, colocando-a entre diversas práticas, sejam esportivas ou recreativas.

Nos últimos dois capítulos, a autora aprofunda o significado do fitness, considerando os significados que os freqüentadores das academias outorgam à sua prática e à convicção de que o mesmo provoca um melhoramento do corpo e de sua energia, entendendo que dedicar tempo ao cuidado do corpo, significa um espaço dedicado a si mesmo. Também se observa o reconhecimento de uma necessidade abstrata de mover-se e como a academia reforça esse desejo individual e paradoxalmente sem exprimir um individualismo.

Roberta examina diferentes aspectos do significado do fitness, o ideal do corpo e da cultura comercial e como acontecem as relações nas academias. Um de seus objetivos é trazer o percurso que os clientes seguem, quando a socialização na academia tem pleno sucesso. A autora mapeia a distribuição do tempo, do espaço e dos exercícios e as condições afetivas destes últimos. Também, aborda o valor do treinamento e de sua racionalização, o disciplinamento do corpo e a escolha de uma prática como o fitness, tendo como objetivo entender o que leva clientes sozinhos a se sentirem envolvidos pela prática do exercício e continuarem praticando e valorizando seus próprios caminhos de treinamento. Descreverei a seguir, um pouco mais detalhadamente, essas considerações.

\section{O MUNDO DO FITNESS}

A academia comumente se relaciona com o fitness. O fitness pode ser entendido como uma prática de uma atividade física que produz uma melhor forma física e de bem-estar, mas por sua vez marca uma diferença com o body-building. Segundo a autora, este pode ser considerado como o "desenvolvimento contemporâneo do fisiculturismo" que se encontra "ligado ao seu entorno por uma procura popular de fortalecimento do corpo que se exprime mediante o desenvolvimento muscular estético direto" (SASSATELLI, 2000, p.183) e em relação àquele, porém há uma concepção funcional do

Movimento, Porto Alegre, v. 13, n. 03, p. 245-259, setembro/dezembro de 2007. 
corpo, que se encontra com o individualismo e no qual se radicaliza o desejo de ter um corpo melhor.

Mas como caracterizar o fitness? As academias de fitness possuem algumas características em comum. A primeira é a oportunidade de treinar-se conforme uma técnica tradicional ${ }^{2}$ ou através de novas combinações que permitem especializar cada treinamento de maneira mais específica. A segunda, uma grande variedade de necessidades individuais e a variedade de técnicas de exercício não implicam a ausência de um mínimo denominador comum que se encarna no significado do fitness. Mas esse significado é ambíguo, seja o estado físico produzido pelo treinamento, seja o próprio treinamento na academia. A terceira característica referese ao prazer e à satisfação da atividade física, mais do que ao próprio esforço ou cansaço.

As academias se caracterizam, também, pelo espaço, pelas ferramentas, pelas atividades e pelos professores. Contudo, estes elementos não são iguais em cada academia, pois há distinções entre as propostas e a clientela que as freqüentam. Mas também muda a percepção do ambiente pelos participantes, os quais falam de um espaço que pode "cortar" e "estranhar" o mundo externo.

A academia é um ambiente de individualismo, no qual cada um pode e deve "concentrar-se sobre si mesmo" e sobre a atividade do próprio corpo. Em geral, o cliente prefere freqüentar apenas por motivo de horário e organização da própria jornada. Mas aqueles clientes que vêm de uma experiência esportiva de equipe se sentem desiludidos e podem deixar de freqüentar a academia, pois o ambiente não oferece una verdadeira experiência "de grupo". Nesse sentido, a academia aponta ao universalismo no qual pretende atingir a todos, como indivíduos, cada um como parte de um universo ilimitado de clientes.

\footnotetext{
${ }^{2}$ Como técnicas tradicionais, a autora quer referir-se a técnicas em comum no âmbito da academia e que possuem um certo tempo de existência, como a aeróbica, o body-building, o stretching. As novas combinações são entendidas como aquelas que misturam entre si a ginástica, a dança, a ioga ou as artes marciais. Aqui devemos considerar que a autora é socióloga e a classificação das técnicas de ginástica não foram elaboradas a partir do conhecimento específico da ginástica, mas sim desde um critério próprio de classificação, a partir de sua pesquisa.
}

Mvimento, Porto Alegre, v. 13, n. 03, p. 245-259, setembro/dezembro de 2007. 
Nesse espaço, os professores desenvolvem uma função fundamental e delicada. Fundamental, pois apresentam a atividade física como uma prática significativa, graduando-a para cada cliente e, delicada, pois promovem a atenção de todos igualmente. Nesse contexto, a maioria dos clientes, poderia "[...] em algumas ocasiões obter o conselho [...] mas não recebia atenção exclusiva" (SASSATELLI, 2000, p. 49).

Aqui, a autora desenvolve o aspecto da cortesia que o professor deve saber dirigir aos clientes. Também, a cortesia ou gentileza existente entre os participantes, permitindo um "conhecimento ligeiro" entre os colegas (SASSATELLI, 2000, p. 53), não obstante possa se tornar uma relação mais duradoura. Desse modo, a academia permite relações interpessoais que, simultaneamente, suspende as diferenças entre os clientes e os mantém longe.

Roberta assinala uma diferença entre o fora-dentro da academia, no qual os vestiários funcionam como um âmbito transformador. Neles, as pessoas transitam ou preparando-se para a atividade física, ou recompondo-se após a mesma, e outorgam a essa transformação tanto um sentido diferente quanto ambíguo. Esta situação limite é definida como um rito de passagem, pois acontece uma cerimônia (seja a troca de roupas, o retoque da maquiagem, o passar o desodorante, o vestir roupas específicas de moda, ${ }^{3}$ etc.), que é clara e inequívoca, no qual os sujeitos entram ou saem, retornando às suas identidades sociais, por exemplo, a pessoa toma banho após o treinamento para voltar ao escritório porque "deve estar apresentável" e, ao mesmo tempo, como "prêmio" por ter feito o treinamento. Esse comportamento marca o caráter transformador e de ligação entre os vestiários e a fadiga.

As academias têm uma divisão espacial específica e a articulação temporal permite que esteja carregada de significado simbólico para reclassificar aquilo que vem do externo e dá um significado específico. Assim, uma boa preparação é tão importante quanto a própria atividade

\footnotetext{
${ }^{3}$ Segundo a autora, isto se observa quando os clientes compram objetos particulares, como bolsas ou tênis e estes funcionam como catalisadores do próprio passar.

Movimento, Porto Alegre, v. 13, n. 03, p. 245-259, setembro/dezembro de 2007.
} 
física. A divisão do espaço é também muito diferenciada em relação ao gênero, a reprodução binária homem-mulher observa-se internamente. As áreas dedicadas ao exercício são mais claramente definidas como, por exemplo, os homens na área de musculação e as mulheres nas salas onde se realizam as diferentes formas de ginástica, mas sobretudo, como âmbitos no qual o corpo perde uma conotação sexual e se torna instrumento de trabalho. Esta tendência é incentivada tanto pelos professores quanto pelos clientes regulares.

Aqui, gostaria de fazer algumas considerações. A primeira é em relação à organização do espaço que é observável. Segundo as idéias de Foucault (2002), através de um poder disciplinar e da organização do tempo e do espaço, o escrutínio do corpo permite um corpo maleável e manipulável que pode ser transformado e aperfeiçoado (FOUCAULT, 2002). Ainda, o corpo, segundo Sant'Anna (2000, p. 52), é algo que "se adquire, se conquista, se constrói", uma vez que se encontra em contínua modificação. Dessa forma, podemos entender que as aparências físicas nunca estão prontas, embora jamais estejam no rascunho.

A segunda consideração que gostaria de destacar é a oposição binária ${ }^{4}$ feminino-masculino. A forma como a autora aborda não permite individualizar as diferenças das mulheres/homens entre si. Quais mulheres ocupam os espaços entendidos como masculinos e vice-versa? Que significados outorgam cada um desses sujeitos à prática de atividades? Que tipo ou modelo de corpo são oferecidos por uma ou outra prática? Elas já são (ou não) conformadas por práticas generificadas?

Por último, apesar de a conotação sexual ser suprimida no âmbito do treinamento, ela pode ser reintroduzida através da sedução, tanto fora quanto dentro da academia, mas com uma matriz heterossexual. Assim, pelo menos oficialmente, a sedução é excluída do ambiente da academia.

Ir à academia é uma decisão voluntária, mas, logo, o próprio ambiente obriga a treinar apesar de não se ter vontade, e isto vem a

${ }^{4}$ Para aprofundar sob oposição binária, ler Louro (1999).

Mvimento, Porto Alegre, v. 13, n. 03, p. 245-259, setembro/dezembro de 2007. 
ser um aspecto que é valorizado. Nessa direção, os objetivos do ideal de corpo são importantes, porém não suficientes. Sassatelli observou também um comportamento expressivo que condensam algumas regras de condutas não-formais (o comportamento, as posições, a expressão facial e o olhar), pois nenhum cliente pode estar sem fazer nada no mesmo espaço que os outros freqüentadores estão se exercitando. Os clientes aprendem, através da expressão ou de um determinado modo de olhar que o exercício é a única ação relevante.

Um modo particular de olhar consiste em olhar-se no espelho e isto é oficialmente prescrito: "devem olhar-se no espelho [...] serve para entender aquilo que está fazendo o teu corpo". Mas no confronto com o espelho, a maior parte dos clientes irregulares tende a afligir-se mais, diferentemente daqueles clientes regulares que consideram que é bom olhar-se para saber "criticar-se para corrigirse". Ainda, o olhar dirigido ao outro deve ser cuidadoso até para não interromper a própria execução do exercício ou como uma intromissão ou falta de respeito. Se o cliente olha demais, parece ter que se justificar verbalmente ou fazer algum sinal.

No espaço da academia, o corpo passa a ser considerado como um corpo-instrumento, um material prático de execução serial. Tanto os clientes quanto os professores fazem referência ao corpo como máquina. O único espaço que foge a esta classificação é o corpo dos vestiários, no limite entre o corpo social e o singular, parece ser naturalizado e nos vestiários o corpo pode ser "suado", "sujo" ou "indecente". Nessa direção, a academia organiza, em seu interior, uma dualidade do corpo em nossa cultura: o corpo como instrumento e como medida do sujeito. O corpo do exercício oferece ao sujeito a possibilidade do controle, enquanto o corpo do vestiário mostra o limite desse controle.

Outro aspecto destacado pela autora é a ironia. Quando os clientes devem realizar uma atividade que, segundo eles, é de difícil execução, surge a ironia verbal. Eles dizem: "é muito difícil" ou afirmam que "o importante é o esforço". A ironia pode ser um modo de não se anular durante a execução ou de mostrar-se o menos possível durante a execução. A ironia e a informalidade também

Novimento, Porto Alegre, v. 13, n. 03, p. 245-259, setembro/dezembro de 2007. 
funcionam como um reconhecimento que relativiza o ideal de corpo, que desde um ponto de vista externo induz a fazer ginástica.

Diferente dos esportes, o fitness permite que o treinamento seja efetivo na medida em que a execução do exercício coincida com a possibilidade de transformar o corpo. Esta possibilidade constitui-se uma meta em si mesma. Essa característica é clara para a maioria dos clientes, mas o melhoramento do corpo pode se encontrar desqualificado pela falta de competição. O fitness deixa de ser efetivo para alguns clientes que não conseguem realizar atividades físicas sem recorrer à competição.

Desse modo, para os clientes tem muita importância a valorização do esforço durante a prática do exercício. O fitness tem sucesso, sobretudo, quando passa a fazer parte de um estilo de vida, quando passa a ser um período prazeroso de uma rotina em que se dedica tempo porque isso é considerado "normal". Assim, para muitos clientes, o fato de freqüentar academias é uma oportunidade de "divertimento" ou de brincadeira. Ainda também a brincadeira é representada como algo "não sério" no qual "os indivíduos abertamente participam pelo prazer de fazê-lo", as pessoas que brincam, não o fazem pelo exercício, mas apenas para divertir-se.

Nesse contexto, construir um programa de treinamento significa fazer com que os clientes percebam os objetivos do programa como seus, como algo profundamente pessoal e, ao mesmo tempo, como um produto de um saber bem definido do qual devem lentamente se apropriar. Nessa direção, é importante que todos os clientes, inclusive os menos envolvidos no treinamento da academia, se exercitem de modo mais "racional" e mais "eficaz" possível, para obter rapidamente um corpo melhor (SASSATELLI, 2000, p. 145).

\section{O CORPO NO FITNESS}

A autovigilância é um dos princípios que dá sentido à atividade da academia, garantindo sua validade. No treinamento, no fitness, encontramos aquilo que Foucault (2002) afirma como a utilização

Movimento, Porto Alegre, v. 13, n. 03, p. 245-259, setembro/dezembro de 2007. 
da disciplina para formar os corpos dóceis através do quadriculamento do próprio corpo. O corpo torna-se mais útil mediante uma forma de exercício que implica uma coerção ininterrupta, constante, e que o vigia sob processo de atividade. Principalmente seu resultado exerce uma codificação que se subdivide em rígidos setores: o tempo, o espaço e o movimento.

Mas, esta disciplina pode ser um pouco desmotivante e cansativa para os participantes e, segundo a autora, aqueles que a abandonam, a colocam em dúvida junto com a própria validade da realização do exercício. Isto se deve ao fato de que o treinamento nas academias utiliza técnicas disciplinares e a decomposição do corpo, contudo, é legitimada conjuntamente com a racionalização. O trabalho do corpo na academia é válido devido à sua eficiência.

Nesse contexto, os professores funcionam como especialistas e a academia nasce dirigindo-se ao indivíduo como consumidor e não como cidadão. A academia não é uma instituição compulsiva e, diferente da escola, não organiza seus freqüentadores em níveis ou cursos, nem organiza suas forças em um somatório como na fábrica. A atividade física que se desenvolve na academia não é uma disciplina em si mesma. Essa instituição configura-se como um espaço de consumo, na qual são os clientes que pagam pelo tempo freqüentado e treinando e é neles que reside, em última análise, o juízo de valor da própria prática.

Como foi mencionado anteriormente, o nível dos treinadores requer um adequado desenvolvimento de conhecimento. Mas, a relação entre professores e clientes se apóia no consenso e na adesão e não se impõe como uma relação de obediência. Os professores não desfrutam de um poder disciplinar, mas de um poder de persuasão. Como um espaço de consumo, a academia não se impõe a quem a freqüenta, ficando a critério do cliente o início e fim da frequiência.

Ainda, o treinamento não implica só um esforço físico ou uma obediência exterior e mecânica. O treinamento implica, também, uma mudança no ponto de vista dos clientes, na medida em que sentem a própria fadiga como uma forma de modificar seu corpo e não como uma imposição. Nessa direção, observa-se uma mudança

Movimento, Porto Alegre, v. 13, n. 03, p. 245-259, setembro/dezembro de 2007. 
nos objetivos dos clientes que primeiro querem emagrecer e depois tonificar o corpo treinado ou "normal", como os clientes regulares acabam por definir seus corpos. Além disso, todos concordam que a academia pode responder a uma multitude de idéias de corpo diferente um do outro, específico e pessoal.

Para alguns clientes manter-se em forma não está necessariamente "ligado à saúde", mas sim ajuda a enfrentar a jornada diária. Concomitantemente, manter-se em forma é compreender a forma corporal como um ideal relativo ao corpo-instrumento, portanto, a saúde é um ideal relativo (SASSATELLI, 2000, p. 166). O ideal de corpo, no treinamento, resulta não só como um equivalente. $\mathrm{O}$ ser saudável e o ter uma forma adequada podem resultar em objetivos importantes em si mesmos porque alguns clientes parecem contrapôlo e preferi-lo à forma. Ainda, é a forma que se configura como o resultado por excelência do treinamento.

Entre os clientes que continuam a preferir a forma, nota-se uma percepção difusa de desejar qualquer coisa que vá além da tentativa própria da atividade do fitness. Por exemplo, Maria sabe que seus desejos em relação à estética são exagerados, ou Mario, que faz fitness, diz que suas preocupações não podem ser predominantes: "na minha idade, o body-building é absurdo". De outro lado, a evocação da saúde assume freqüentemente um significado oposto à forma, como aquilo que oferece um reconhecimento de funcionalidade interna do corpo. Assim, muitos clientes, sabendo da superficialidade do estético, referem-se à saúde para justificar a estética (SASSATELLI, 2000, p. 167).

Desse modo, um corpo em forma é o produto de uma atividade física bem organizada e instrumental. Durante a atividade, o corpo se configura como um instrumento de uso mais do que um bem a ser cuidado. O produto de tal trabalho corresponde, por sua vez, a uma visão instrumental do corpo, e que tem a idéia que o corpo deva ser considerado ativo como reserva de energia de desfrutar na vida cotidiana. A dupla instrumentalidade do fitness, o instrumento do exercício e a instrumentalidade do corpo que vem assim produzido tornam-se um valor.

Movimento, Porto Alegre, v. 13, n. 03, p. 245-259, setembro/dezembro de 2007. 
Quem pratica fitness regularmente termina não apenas encontrase mais tônico e mais moderado nas suas práticas ou condutas, mas é também convidado a definir o significado de tais transformações. Essas re-significações acontecem pelas possibilidades de melhorar a si mesmo, através de um maior controle do próprio corpo. O corpo vem descrito como uma máquina que funciona em base a uma particular economia de energia: queimando e consumindo a própria energia ao fazer exercícios, o corpo está apto a adquirir mais energia. Os treinadores recorrem com frequiência a estas afirmações. Afirmam também, que os clientes "descarregam a tensão mental" e há "um dispêndio de energia que com um banho se recupera, enquanto que aquela parte da energia negativa acumulada com o trabalho, com um banho não vai embora, só vai fora com a academia". "O cansaço da academia eu o procuro: escolho usar a energia aqui na academia - para ter mais depois!" (SASSATELLI, 2000, p. 181).

Essa energia adquirida com o treinamento é uma energia positiva, não só porque se opõe à tensão cotidiana, mas porque é dócil, disponível e, efetivamente, utilizável pelo sujeito. Assim, os clientes dizem ter adquirido energia. Alguns, entre os mais jovens, não tinham se "dado conta", mas confessam que estavam se tornando mais debilitados para fazer algumas coisas (SASSATELLI, 2000, p. 182).

O corpo ou mais especificamente as partes e as funções do corpo individualizadas no exercício são consideradas plásticas, ou seja, é possível desenvolvê-las e modificá-las. Deste modo, o treinamento representa assim não só o instrumento, mas o limite da plasticidade do corpo. Assim, por exemplo, Maria, é a mais satisfeita da academia, não porque produz aquele corpo "impossível", mas porque treinando, obteve um corpo melhor, "àquele com relação a sua energia" (SASSATELLI, 2000, p. 187).

O treinamento representa não só o instrumento, também o limite da plasticidade do corpo. Nesta plasticidade, a mudança não é qualquer mudança, mas é uma em particular, no qual o corpo mostra seu limite. Os clientes valorizam a mudança natural e não a cirúrgica: "eu mudei porque fiz uma atividade". Ainda, o treinamento não só é

Movimento, Porto Alegre, v. 13, n. 03, p. 245-259, setembro/dezembro de 2007. 
racional, exato e eficaz, mas também é justo, correto e virtuoso. Assim, através da prática se concebe o fitness como um regime de vida que produz um equilíbrio, o qual corrige a vida insalubre de fora da academia, a vida na cidade. Ir a uma academia favorece a uma organização em outros aspectos da vida, tais como a alimentação; assim, Alessia diz que ajuda a "não fumar mais" e a "comer melhor", etc. Resumindo, muitos clientes afirmam que a academia tem ajudado a reestruturar os próprios costumes, contendo ou modificando os costumes danosos e induzindo a novas regras de conduta.

Deste modo, no contexto do lazer, as práticas são rotinizadas e incorporadas na vida do dia-a-dia do sujeito, e a prática dessas atividades aparece como "um modo a mais" que permite expressar um determinado estilo de vida. O estilo de vida, segundo Stigger (2001, p. 213), constitui a "maneira de ser" de um sujeito que não deixa de ser construída pelo espaço social no qual ele se encontra. Sassatelli (2000) destaca que o "estilo de vida" compreende uma modalidade de problematização da escolha individual em função de ordenar harmonicamente uma história sobre o gosto e a expressão da identidade pessoal.

Nessa direção, os freqüentadores de academias valorizam o treinamento, pois com ele o sujeito não procura um status original, mas encontra um equilíbrio, descobrindo o próprio corpo. Porém, este equilíbrio não é uma superação do dualismo corpo-mente, mas uma espécie de balanço, no qual se adere a uma nova forma de governo do corpo que gera aumento de energia e de capacidade. Os discursos tanto de professores quanto de clientes contribuem para um processo que vai transformando as práticas recreativas do cuidado do corpo.

Desse modo, os clientes entendem como "falsa e superficial" aquela imagem da moda da academia, pois para eles/as treinar permite "pensar com a própria cabeça", porque "uma pessoa se deve sentir como é" (SASSATELLI, 2000, p. 199). Ainda, afirmam que, no momento que começaram, queriam melhorar, cuidar-se e pensar em si mesmos, e então, começaram pelo corpo. Mas, simultaneamente, descobriram de maneira "casual e espontânea" um conhecimento e uma energia que não esperavam. Nesse sentido, a fadiga se configura também como uma aprendizagem que requer de um sujeito ativo e participante. Este quando treina é simultaneamente transformado.

Movimento, Porto Alegre, v. 13, n. 03, p. 245-259, setembro/dezembro de 2007. 


\section{CONCLUSÃO}

Como um bom e instigante estudo, a obra de Sassatelli nos provoca a pensar e a questionar. Pergunto-me: quais são as possibilidades pedagógicas deste ambiente? Como se constitui um grupo nesse espaço? Como se estabelecem as relações entre os membros desse grupo? Que significados esses sujeitos outorgam à própria prática?

O estudo profundo e detalhado analisado aqui favorece, por um lado, o desenvolvimento/entendimento da academia como um espaço comercial, no qual se promove um adestramento e um culto ao corpo. Por outro lado, devido aos objetivos e delimitações da pesquisa, torna-se difícil identificar/mapear as questões sociais/ afetivas e de vínculos pedagógicos que podem ocorrer em um espaço no qual os limites do dentro-fora não parecem ser tão definidos. A autora desenvolve esse aspecto como uma fronteira definitiva entre o interior-exterior da academia, mas será que é possível demarcála dessa maneira? Que aspectos pertencem à cultura, à sociedade, ao bairro no qual a academia está inserida? Esses aspectos culturais atravessam ou não as paredes da academia?

Ainda, é possível perguntar-se: será que a aprendizagem corporal é sempre uma aprendizagem por imitação e individual? Segundo as reflexões de Waquant (2002), será que a aprendizagem corporal da academia é oriunda de uma lógica simples que só é aprendida através da ação? Nessa direção, o autor realizou um estudo numa academia de body-building (e não de fitness) observando como um esporte individual como o boxe poderia ter uma aprendizagem de grupo e destacando o "paradoxo de um esporte ultra-individual, cuja aprendizagem é totalmente coletiva" (WAQUANT, 2002, p. 120).

Para concluir esta resenha, gostaria de considerar que o espaço da academia constitui um espaço tão banal e, por sua vez, um espaço ou uma instituição complexa carregada de múltiplos significados. Espaço no qual, cada sujeito outorga um significado diferente segundo

Movimento, Porto Alegre, v. 13, n. 03, p. 245-259, setembro/dezembro de 2007. 
suas vivências. Gostaria de explicitar a importância de um estudo etnográfico no espaço da academia sob o aspecto de uma cultura comercial a qual também possibilita a partir dele, realizar outros futuros trabalhos sob outros focos de pesquisa.

Observar em detalhe o trabalho de Sassatelli nos desafia, em múltiplos sentidos, pela temática, pela abordagem, pela metodologia, pela profundidade teórica e empírica a todos nós, Professores de Educação Física, a realizar estudos etnográficos nesses contextos sociais, devido à ausência de pesquisas e da temática abordada. Sem dúvidas, este estudo constitui um passo fundamental e original na realização de pesquisas etnográficas no âmbito da academia ou contextos sociais semelhantes.

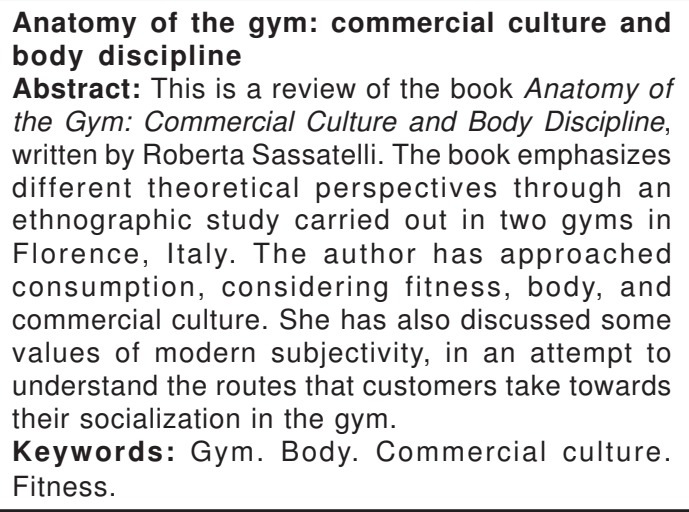

Anatomía del gimnasio: cultura comercial y
disciplina del cuerpo
Resumen: Esta reseña se propone en presentar
el libro titulado "Anatomia del Gimnasio: Cultura
Comercial y Disciplina del Cuerpo" de Roberta
Sassatelli. A obra destaca diferentes perspectivas
teoricas, por medio de un estudio etnográfico en
dos gimnasios de Florencia, Italia. La autora realiza
un abordaje sobre el consumo, observando el
fitness, el cuerpo, y la cultura comercial. Aun, discute
algunos valores de la subjetividad moderna,
buscando comprender el precurso que los clientes
siguen en el gimnasio en su socializacion.
Palabras clave: Gimnasio. Cuerpo. Cultura comercial.
Cultura Fisica.

Movimento, Porto Alegre, v. 13, n. 03, p. 245-259, setembro/dezembro de 2007. 


\section{REFERÊNCIAS}

FOUCAULT, M. Vigiar e Punir. História das Prisões. 26. ed. Petrópolis, RJ: Vozes, 2002.

LOURO, L. G. Gênero, Sexualidade e Educação: uma perspectiva pósestruturalista. 4. ed. Petrópolis: Vozes, 2001.

SANT'ANNA, D. Descobrir o Corpo: uma história sem fim. Educação \& Realidade, Porto Alegre, v. 25, n. 2, p. 49-50, jul./dez., 2000.

SASSATELLI, R. Anatomia della Palestra: Cultura Commerciale e disciplina del Corpo. Bologna: II Mulino, 2000.

STIGGER, M. P. Esporte, Lazer e Estilos de Vida: um estudo etnográfico. Campinas, SP: Autores Associados: CBCE, 2002.

WACQUANT, L. Corpo e Alma: Notas etnográficas de um aprendiz de boxe. Trad. Ângela Ramalho. Rio de Janeiro: Relume Dumará, 2002.

Movimento, Porto Alegre, v. 13, n. 03, p. 245-259, setembro/dezembro de 2007. 